\title{
Three-dimensional skeletal mandibular changes associated with Herbst appliance treatment
}

\author{
B. Q. Souki ${ }^{1}$ (D) | P. L. C. Vilefort ${ }^{1}$ | D. D. Oliveira ${ }^{1}$ | I. Andrade Jr ${ }^{1}$ | A. C. Ruellas $^{2}$ | \\ M. S. Yatabe ${ }^{3}$ | T. Nguyen ${ }^{4}$ | L. Franchi ${ }^{5}$ | J. A. McNamara Jr ${ }^{6}$ | L. H. S. Cevidanes ${ }^{6}$
}

${ }^{1}$ Pontifical Catholic University of Minas Gerais, Belo Horizonte, Brazil

${ }^{2}$ Federal University of Rio de Janeiro, Rio de Janeiro, Brazil

${ }^{3}$ University of Sao Paulo, Bauru, Brazil

${ }^{4}$ University of North Carolina, Chapel Hill, NC, USA

${ }^{5}$ University of Florence, Florence, Italy

${ }^{6}$ University of Michigan, Ann Arbor, MI, USA

Correspondence

B. Souki, Pontifical Catholic University of Minas Gerais, Belo Horizonte, Brazil.

Email: souki.bhe@terra.com.br
Objectives: Three-dimensional evaluation of skeletal mandibular changes following Herbst appliance treatment.

Setting and Sample Population: Retrospective case-control study, based on a sample size calculation. Twenty-five pubertal patients treated with Herbst appliance (HAG), and 25 matched Class II patients who received other non-orthopaedic dental treatments (CG).

Material and Methods: Three-dimensional models were generated from pretreatment (TO) and post-treatment (T1) cone beam computed tomograms. Volumetric registration on the cranial base was used to assess mandibular displacement; volumetric regional registration was performed to evaluate mandibular growth. Quantitative measurements of $\mathrm{X}, \mathrm{Y}, \mathrm{Z}$ and 3D Euclidian changes, and also qualitative visualization by colour-mapping and semi-transparent overlays were obtained.

Results: Downward displacement of the mandible was observed in both HAG and CG (2.4 $\mathrm{mm}$ and $1.5 \mathrm{~mm}$, respectively). Significant forward displacement of the mandible was observed in the HAG $(1.7 \mathrm{~mm})$. HAG showed greater 3D superior and posterior condylar growth than the CG $(3.5 \mathrm{~mm}$ and $2.0 \mathrm{~mm}$, respectively). Greater posterior growth of the ramus was noted in the HAG than in CG.

Conclusions: Immediately after Herbst therapy, a significant mandibular forward displacement was achieved, due to increased bone remodelling of the condyles and rami compared to a comparison group. Three-dimensional changes in the direction and magnitude of condylar growth were observed in Herbst patients.

KEYWORDS

Angle Class II, growth and development, Herbst appliance, malocclusion

\section{1 | INTRODUCTION}

The primary goal of Herbst appliance therapy is to correct Class II malocclusion and improve facial convexity. ${ }^{1-3}$ Numerous clinical studies $^{4-9}$ have reported a short-term increase in mandible length and forward displacement of the mandible. Furthermore, histological animal studies corroborated these findings by showing growth modification of the mandibular condyle and ramus following Herbst treatment. ${ }^{10,11}$
Much debate still exists, however, as to whether the bite jumping mechanism has the capacity of stimulating greater mandibular growth and consequently forward displacement of the mandible. ${ }^{12-15}$

To date, the majority of Herbst studies were performed using two-dimensional (2D) cephalometric imaging, an approach that cannot explain adequately the complex interactions of three-dimensional (3D) changes that occur with growth and treatment. ${ }^{16}$ In a recently published systematic review ${ }^{14}$ concerning the changes in the TMJ 
morphology in Class II patients treated with fixed mandibular repositioning evaluated with 3D imaging, the authors concluded that previous literature has "failed to establish conclusive evidence of the exact nature of TMJ tissue response." The authors suggested the development of an adequate sample size cone beam computed tomography (CBCT) 3D investigation, using valid and reliable superimposition technique to quantify bone remodelling.

Therefore, the aim of this retrospective study was to compare the mandibular skeletal changes in pubertal Class II patients treated with Herbst appliance vs orthopaedically untreated Class II controls, using a 3D virtual modelling protocol.

\section{2 | MATERIALS AND METHODS}

\section{1 | Sampling}

This investigation is a retrospective study that followed the ethical standards of the institutional review board of the Pontifical Catholic University of Minas Gerais, Brazil. The primary focus was to evaluate increases in condylar growth during Herbst therapy. Based on the standard deviation of $1.85 \mathrm{~mm}$ reported by Pancherz et al., ${ }^{17}$ an alpha significance level of 0.05 and a power of 0.80 to detect changes of $1.5 \mathrm{~mm}$, a sample size of 25 patients per group was calculated. The total sample included 50 skeletal Class II pubertal patients.

Patients had been treated at the graduate program in orthodontics of the Pontifical Catholic University of Minas Gerais, Brazil and were considered eligible for this study when they had routine pre-treatment (TO) and post-treatment (T1) CBCTs acquired for the purpose of the orthodontic or dental diagnosis and treatment planning. Moreover, the patients at TO were as follows: (i) in the permanent dentition; (ii) age between 12 and 16 years old; (iii) in the pubertal growth period, as determined by the Cervical Vertebrae Maturation Method; ${ }^{18}$ (iv) with Class II division 1 malocclusion characterized by full Class II molar relationships, and canines that had at least 4-mm sagittal discrepancy to achieve a Class I relationship; (v) and an improved facial profile when the mandible was postured in a forward position. ${ }^{19}$

Twenty-five patients who had received one-step mandibular activation with a cantilever Herbst to obtain a Class I canines relationship were included in the Herbst appliance group (HAG). The remaining 25 subjects were assigned to the comparison group (CG). The patients in the CG had the need for other dental treatments or an orthodontic levelling and alignment of maxillary teeth, without dentofacial orthopaedic effects. At TO, no significant different morphologic characteristics were detected between HAG and CG patients $(P>.05)$. The Herbst patients presented with an ANB of $6.4^{\circ} \pm 1.2^{\circ}$, SNB of $72.4^{\circ} \pm 2.1^{\circ}$ and SNGoGn of $32.1^{\circ} \pm 2.2^{\circ}$. The comparison group patients had an ANB of $5.9^{\circ} \pm 1.0^{\circ}$, SNB of $73.0^{\circ} \pm 3.0^{\circ}$ and $\mathrm{SNGoGn}$ of $32.0^{\circ} \pm 2.6^{\circ}$.

\section{2 | Image acquisition}

Cone beam computed tomographic (CBCT) scans had been taken for all subjects, using an iCat machine (Imaging Sciences International, Hatfield, PA), with a 40 -second scan, a $23 \times 17-\mathrm{cm}$ field of view (FOV) and a voxel size of $0.3 \mathrm{~mm}$. In the HAG, the scans were taken before HA delivery (TO) and after $7.9 \pm 0.4$ months of treatment (T1). In the CG, the scans were taken at two time-points: at baseline (TO), and at the end of the orthodontic or prosthetic treatment, during the followup of impacted canine treatment, or after maxillary cyst marsupialization. The average time between films in CG was $8.4 \pm 1.3$ months. All patients had been instructed to bite into centric occlusion during scan acquisition.

\section{3 | Image analysis}

The 3D image analysis procedures followed the protocol that has been published elsewhere, ${ }^{20-23}$ which included the following: (i) construction of 3D surface models; ${ }^{20}$ (ii) 3D model orientation in the Cartesian planes; ${ }^{20,21}$ (iii) 3D cranial base superimposition for the mandibular displacement analysis; ${ }^{20}$ (iv) 3D mandibular regional superimposition (manual approximation and automated registration on the body of the mandible) for the mandibular growth analysis; ${ }^{22}(\mathrm{v})$ qualitative assessments using 3D mesh surface models; ${ }^{20,23}$ and (vi) quantitative measurements using Pick-n'-Paint and Q3DC tools of 3D Slicer. ${ }^{20,24}$

\section{4 | Statistical analysis}

Fourteen scans were selected randomly, and models were rebuilt and re-measured by two blinded investigators after a two-week interval. Random error was measured according to Dahlberg's formula, and both intra- and interobserver agreement measurements were tested using intraclass correlation coefficients (ICC).

Systematic error was assessed using the paired $t$ test. To evaluate the differences between the Herbst and Comparison groups with regard to T1-T0 changes, independent sample $t$ tests with HolmBonferroni correction for multiple tests were used. Analysis of covariance (ANCOVA) was conducted with the mean TO-T1 change in the several ROI's as the dependent variables, group of treatment as the independent variable and SNGoGn angle as the covariate. Chi-square test was used to assess differences in the gender distribution. The level of significance was set at 0.05 .

\section{3 | RESULTS}

The two groups were matched by gender (HAG, 11 males vs CG 15 males, chi-square $P>.05)$, chronological age (13.7 \pm 1.8 years for HAG vs $13.9 \pm 1.2$ years for $C G)$, stage of dental development, stage of skeletal maturation (88\% in CS3 or CS4) and by length of observational period ( 8 months). In each group, two patients were in stage CS2 and one patient was in stage CS5.

The ICCs were greater than 0.89 for both intra- and interobserver repeated measurements. There were no statistically significant systematic errors between the two measurements performed by the same operator $(P>.05)$, and random error values varied between $0.07 \mathrm{~mm}$ (3D condyle anterior) and $0.18 \mathrm{~mm}$ (3D condyle superior). 
TAB LE 1 Comparison of mandibular displacement (T1-TO) in Herbst appliance and Comparison groups ( $t$ test and ANCOVA ${ }^{\mathrm{a}}$ ). Cranial base superimposition.

\begin{tabular}{|c|c|c|c|c|c|c|c|c|c|c|}
\hline ROI & Coordinates & Groups & Mean & SD & Mean difference & $\mathrm{Cl} 95 \%$ & & $\begin{array}{l}T \text { test } \\
P \text { value }\end{array}$ & $\begin{array}{c}\text { F } \\
\text { Groups }\end{array}$ & $\begin{array}{c}F \\
\text { SNGoGn }\end{array}$ \\
\hline \multirow[t]{8}{*}{ Pogonion } & \multirow[t]{2}{*}{$x$} & Herbst & -0.37 & 0.65 & \multirow[t]{2}{*}{-0.29} & \multirow{2}{*}{-0.85} & \multirow[t]{2}{*}{0.25} & \multirow[t]{2}{*}{.279} & \multirow[t]{2}{*}{2.056} & \multirow[t]{2}{*}{0.073} \\
\hline & & Comparison & -0.08 & 0.46 & & & & & & \\
\hline & \multirow[t]{2}{*}{$\mathrm{Y}$} & Herbst & 2.20 & 1.31 & \multirow[t]{2}{*}{1.66} & \multirow[t]{2}{*}{0.74} & \multirow[t]{2}{*}{2.60} & \multirow[t]{2}{*}{$.001^{* *}$} & \multirow[t]{2}{*}{$14.396^{* *}$} & \multirow[t]{2}{*}{0.088} \\
\hline & & Comparison & 0.54 & 1.34 & & & & & & \\
\hline & \multirow[t]{2}{*}{ Z } & Herbst & 2.37 & 1.60 & \multirow[t]{2}{*}{0.90} & \multirow[t]{2}{*}{-0.21} & \multirow[t]{2}{*}{2.03} & \multirow[t]{2}{*}{.110} & \multirow[t]{2}{*}{2.134} & \multirow[t]{2}{*}{1.897} \\
\hline & & Comparison & 1.47 & 1.64 & & & & & & \\
\hline & \multirow[t]{2}{*}{$3 D$} & Herbst & 3.68 & 1.55 & \multirow[t]{2}{*}{1.46} & \multirow[t]{2}{*}{0.42} & \multirow[t]{2}{*}{2.49} & \multirow[t]{2}{*}{$.007^{* *}$} & \multirow[t]{2}{*}{$8.052^{* *}$} & \multirow[t]{2}{*}{1.833} \\
\hline & & Comparison & 2.22 & 0.43 & & & & & & \\
\hline \multirow[t]{2}{*}{ Mandible } & \multirow[t]{2}{*}{ Pitch } & Herbst & 0.06 & 0.60 & \multirow[t]{2}{*}{0.35} & \multirow[t]{2}{*}{-0.20} & \multirow[t]{2}{*}{0.90} & \multirow[t]{2}{*}{.207} & \multirow[t]{2}{*}{1.853} & \multirow[t]{2}{*}{0.926} \\
\hline & & Comparison & -0.29 & 0.95 & & & & & & \\
\hline
\end{tabular}

Pitch is defined as clockwise and/or counterclockwise rotation in a lateral view.

Entries in bold highlight the comparison in which significant difference was found.

aANCOVA indicates analysis of covariance; SD, standard deviation; Cl 95\%, confidence interval of 95\%; $\mathrm{X}$, mesial-lateral; $\mathrm{Y}$, anterior-posterior; Z superiorinferior; (+), rightward, forward, downward, clockwise rotation; (-), leftward, backward, upward, counterclockwise rotation.

${ }^{*} P<.05 ;{ }^{* *} P<.01$.

Mandibular displacement and rotation in HAG and CG is shown in Table 1. The condylar and ramal growth changes in the right and left side were symmetrical, with no statistically significant difference between sides in both groups (Table 2). Mean differences in mandibular and ramal growth between the HAG and CG are reported in Table 3.

Figure 1 shows the mandibular displacement with the cranial base superimposition of HAG and CG individuals, while Figures 2 and 3 show the pattern of growth of the condyle and rami with colour-coded regional superimposition. The skeletal mandibular changes associated with Herbst treatment can be summarized as follows:

\section{1 | The forward displacement of the mandible was greater in the HAG}

Pogonion showed a significant anterior displacement ( $y$-axis) in the HAG (HAG, $2.2 \mathrm{~mm}$ vs CG, $0.5 \mathrm{~mm}$; mean difference, $1.7 \mathrm{~mm}$; Table 1, Figure 1). The $3 \mathrm{D}$ displacement was significantly greater in the HAG (HAG, $3.7 \mathrm{~mm}$ vs CG, $2.2 \mathrm{~mm}$; mean difference, $1.5 \mathrm{~mm}$ ). Both groups showed a similar $(P>.05)$ downward ( $z$-axis) mandibular displacement (2.4 $\mathrm{mm}$ vs $1.5 \mathrm{~mm}$ in the HAG and CG, respectively). Changes in mandibular pitch were minimal in both groups (mean $0.1^{\circ}$ clockwise; $95 \% \mathrm{Cl}$ from $-2.1^{\circ}-2.3^{\circ}$ in the HAG vs $0.3^{\circ}$ counterclockwise $95 \% \mathrm{Cl}$ from $-2.5^{\circ}-2.0^{\circ}$ in the CG group). Fifteen patients in the HAG showed clockwise pitch, while 11 patients in the CG showed clockwise pitch.

\subsection{Patients in the HAG presented a different pattern of condylar growth}

The 3D net growth of condyles in all surfaces was significantly greater in the HAG (superior, $1.4 \mathrm{~mm}$; lateral $1.1 \mathrm{~mm}$; medial, $0.5 \mathrm{~mm}$; anterior $1.3 \mathrm{~mm}$; posterior, $1.2 \mathrm{~mm}$; Table 3, Figures 2 and 3), with the exception of the medial pole. Patients in the HAG showed more posterior and superior condylar growth than the CG $(P<.05)$, with the exception of the vertical growth of the medial condylar pole (Table 3 ). The right-left lateral skeletal changes did not show statistically significant differences between groups.

\subsection{The posterior surface of the rami in the HAG showed greater amounts of posterior growth}

The Herbst group showed a statistically significant greater net change for the lower region of the ramus in the projected $Y$ component $(0.6 \mathrm{~mm}$; Figures 3$)$. The vertical and lateral growth of the mandibular ramus ( $z$-axis and $x$-axis, respectively) was not significantly different between the groups. Three-dimensional net changes in the superior (neck) region of the rami did not show statistically significant differences between HAG and CG.

\section{4 | DISCUSSION}

Previous reports on the net gain of mandibular advancement are controversial. Pancherz $z^{8}$ reported $2.5 \mathrm{~mm}$ of Pogonion advancement when compared to an untreated sample of Class II sample after 6 months of HA treatment. However, 16 years later, Pancherz et al. ${ }^{17}$ reported only a $0.9 \mathrm{~mm}$ gain in the position of Pogonion in the Herbst group in comparison with values from the Bolton Standards $(2.2 \mathrm{~mm}$ vs $1.3 \mathrm{~mm}$ ). De Almeida et al. ${ }^{25}$ did not find statistical difference in the Pogonion position between treated and control patients. In our study, the net mean of $1.5 \mathrm{~mm}$ increment (HAG $3.7 \mathrm{~mm}$ vs CG $2.2 \mathrm{~mm}$ ) in mandibular anterior displacement in the projected $y$-axis may have contributed to facial profile improvement, as well as correction of the malocclusion that was observed clinically in all HAG patients. 
TAB LE 2 Condylar and rami growth after Herbst appliance therapy with the comparison between right and left sides ( $t$ test). Mandibular regional superimposition.

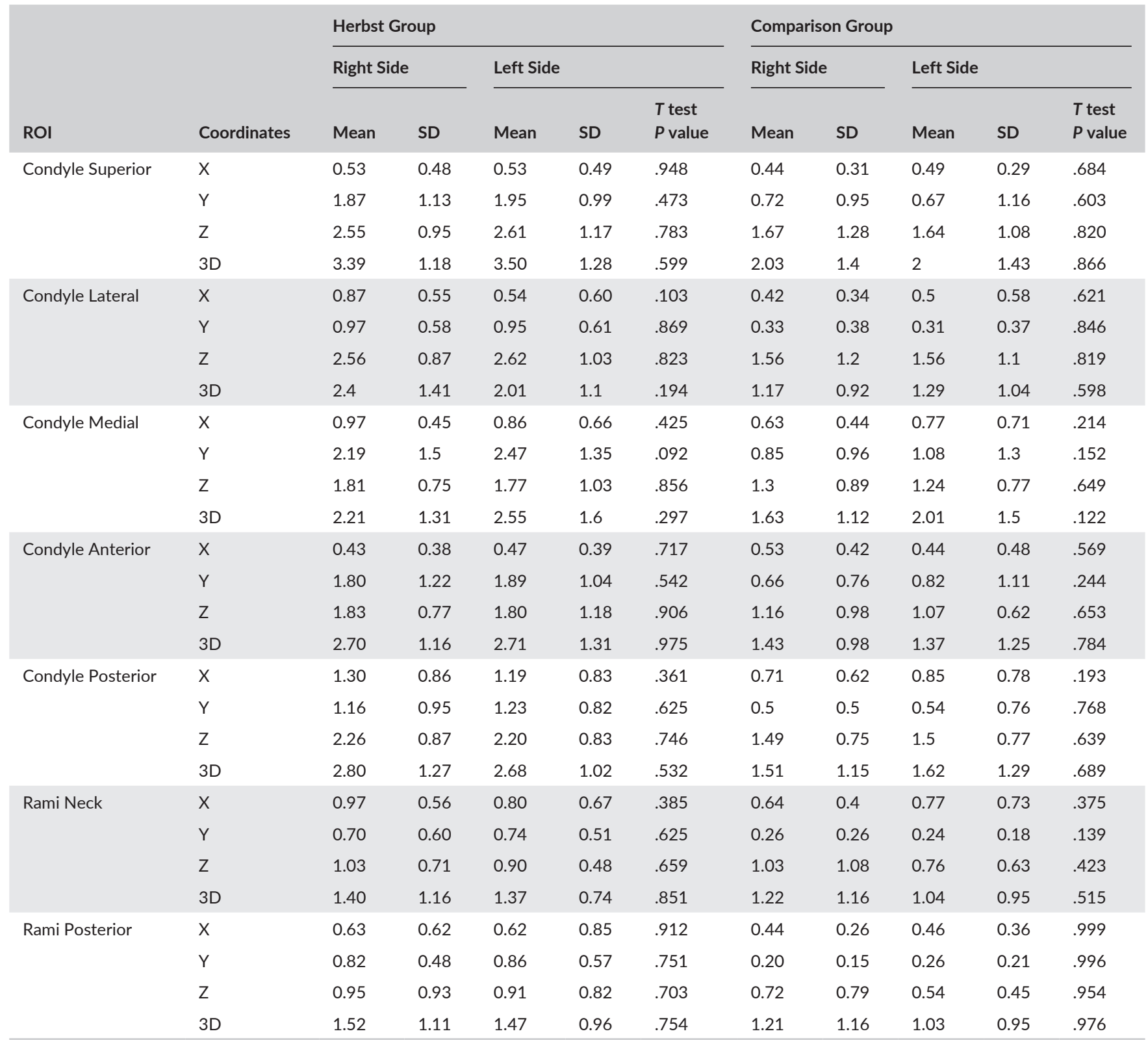

$\mathrm{X}$ : mesial-lateral, Y: anterior-posterior; Z: superior-inferior.

(+): lateral, backward, upward.

Our findings concerning the $3 D$ directional components of the mandibular growth and displacement relative to the cranial base revealed $2.4 \mathrm{~mm}$ downward displacement of the Pogonion region. Pancherz et al. ${ }^{17}$ reported that Herbst treatment produced $3.9 \mathrm{~mm}$ of downward displacement of the Pogonion region. Differences in appliance design using mandibular first premolars as anchorage in the Pancherz study ${ }^{17}$ vs first molars in the present study may have resulted in differences on the point of force application and improved control of vertical growth in the present study.

The results of this investigation suggest that condylar and ramal growth are modified with Herbst appliance treatment. Our findings indicated that in the superior region and the posterior surface of the condyles showed $1.4 \mathrm{~mm}$ and $1.2 \mathrm{~mm}$ greater growth in the HAG than the CG over an 8-month period. The 3D components of bone remodelling, however, were not uniform along the whole condylar surface. As was expected from a morphological and functional standpoint, changes in the shape of the mandible typically take place during normal growth. Such morphological changes in the shape and position of the condyles were observed in most of the HAG and CG subjects.

The amount of effective condylar growth in Herbst subjects found in the current 3D investigation $(1.4 \mathrm{~mm}$ in the superior aspect of the condyles) was very close to data reported previously in 2D cephalometric studies that used Condylion as reference landmark. Pancherz ${ }^{17}$ reported $1.8 \mathrm{~mm}$ of effective condylar growth in 
TAB LE 3 Comparison of condylar and rami changes (T1-TO) in Herbst appliance and Comparison groups ( $(t$ test and ANCOVA $)$.

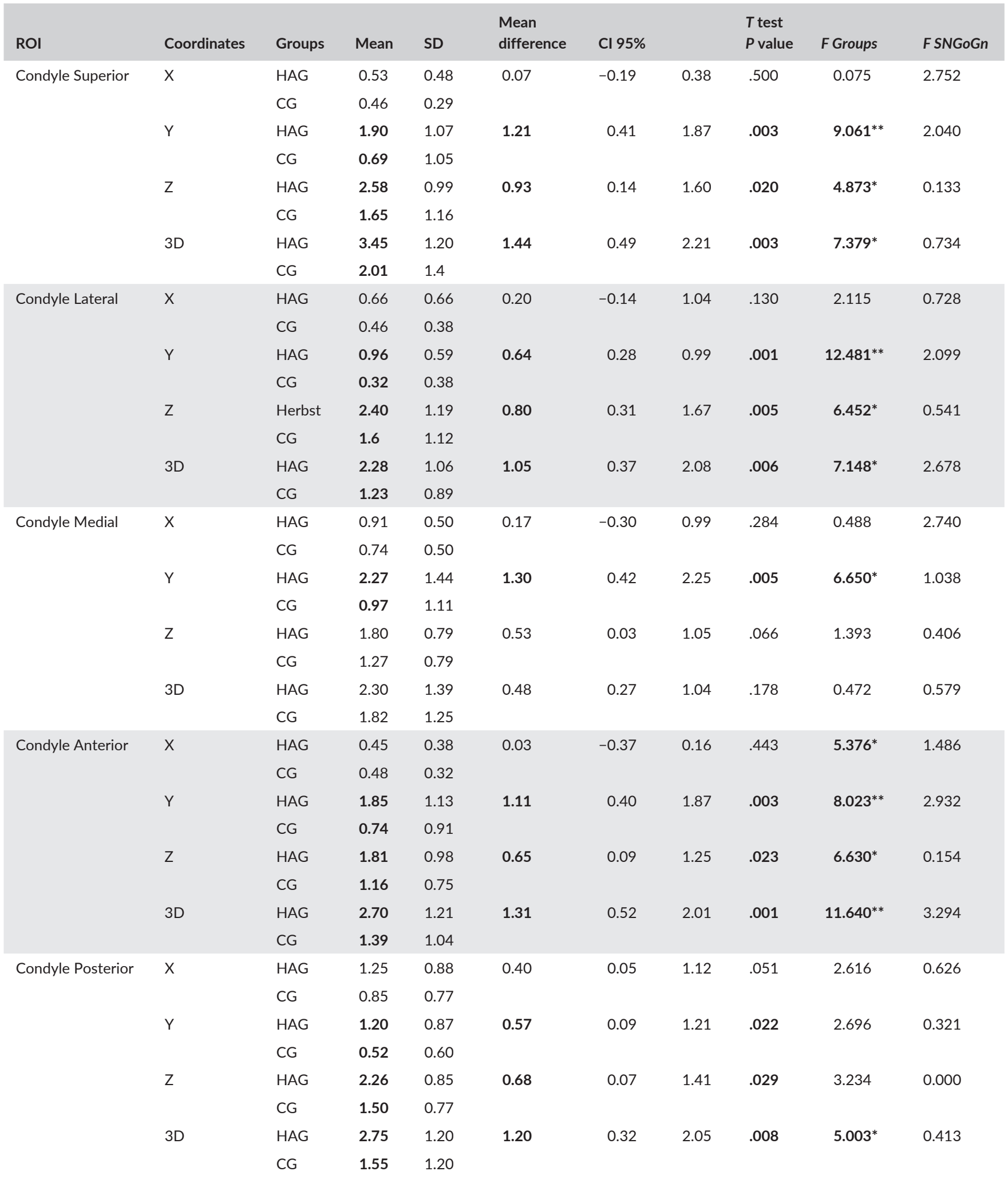

(Continues)

the Herbst groups. Another study ${ }^{25}$ found $2.5 \mathrm{~mm}$ of supplementary mandibular length increase in Herbst patients. The relatively smaller net differences in condylar growth observed in the present study can be explained by: (i) the stage of skeletal maturation of the patients; (ii) differences in the control groups; and (iii) the methods of registration and measurement.

The short observational period in the current investigation could account for the relatively small skeletal changes. However, previous Herbst 
TABLE 3 (Continued)

\begin{tabular}{|c|c|c|c|c|c|c|c|c|c|c|}
\hline ROI & Coordinates & Groups & Mean & SD & $\begin{array}{l}\text { Mean } \\
\text { difference }\end{array}$ & $\mathrm{Cl} 95 \%$ & & $\begin{array}{l}T \text { test } \\
P \text { value }\end{array}$ & F Groups & F SNGoGn \\
\hline \multirow[t]{6}{*}{ Rami Neck } & $x$ & HAG & 0.85 & 0.58 & 0.14 & -0.08 & 0.61 & .131 & 0.313 & 0.993 \\
\hline & \multirow[t]{2}{*}{ Y } & HAG & 0.72 & 0.53 & \multirow[t]{2}{*}{0.46} & \multirow[t]{2}{*}{0.01} & \multirow[t]{2}{*}{0.68} & \multirow[t]{2}{*}{.059} & \multirow[t]{2}{*}{2.704} & \multirow[t]{2}{*}{0.816} \\
\hline & & CG & 0.26 & 0.18 & & & & & & \\
\hline & z & CG & 0.89 & 0.63 & 0.14 & -0.58 & 0.58 & .996 & 0.007 & 0.147 \\
\hline & \multirow[t]{2}{*}{$3 D$} & HAG & 1.29 & 0.85 & \multirow[t]{2}{*}{0.16} & \multirow[t]{2}{*}{-0.51} & \multirow[t]{2}{*}{0.89} & \multirow[t]{2}{*}{.597} & \multirow[t]{2}{*}{0.025} & \multirow[t]{2}{*}{0.002} \\
\hline & & CG & 1.13 & 0.94 & & & & & & \\
\hline \multirow[t]{5}{*}{ Rami Posterior } & \multirow[t]{2}{*}{$x$} & HAG & 0.63 & 0.67 & \multirow[t]{2}{*}{0.17} & \multirow[t]{2}{*}{-0.19} & \multirow[t]{2}{*}{0.57} & \multirow[t]{2}{*}{.324} & 0.007 & 0.031 \\
\hline & & CG & 0.46 & 0.26 & & & & & & \\
\hline & & CG & 0.56 & 0.34 & & & & & & \\
\hline & $3 D$ & HAG & 1.49 & 0.99 & 0.31 & -0.67 & 1.38 & .487 & $5.687^{*}$ & 0.113 \\
\hline & & CG & 1.18 & 0.9 & & & & & & \\
\hline
\end{tabular}

Entries in bold highlight the comparison in which significant difference was found.

${ }^{a}$ ANCOVA indicates analysis of covariance; SD, standard deviation; $\mathrm{Cl} 95 \%$, confidence interval of $95 \%$; $\mathrm{X}$, mesial-lateral; $\mathrm{Y}$, anterior-posterior; Z superior-inferior; (+), rightward, forward, downward, clockwise rotation; (-), leftward, backward, upward, counterclockwise rotation, ${ }^{*} P<.05 ;{ }^{* *} P<.01$.
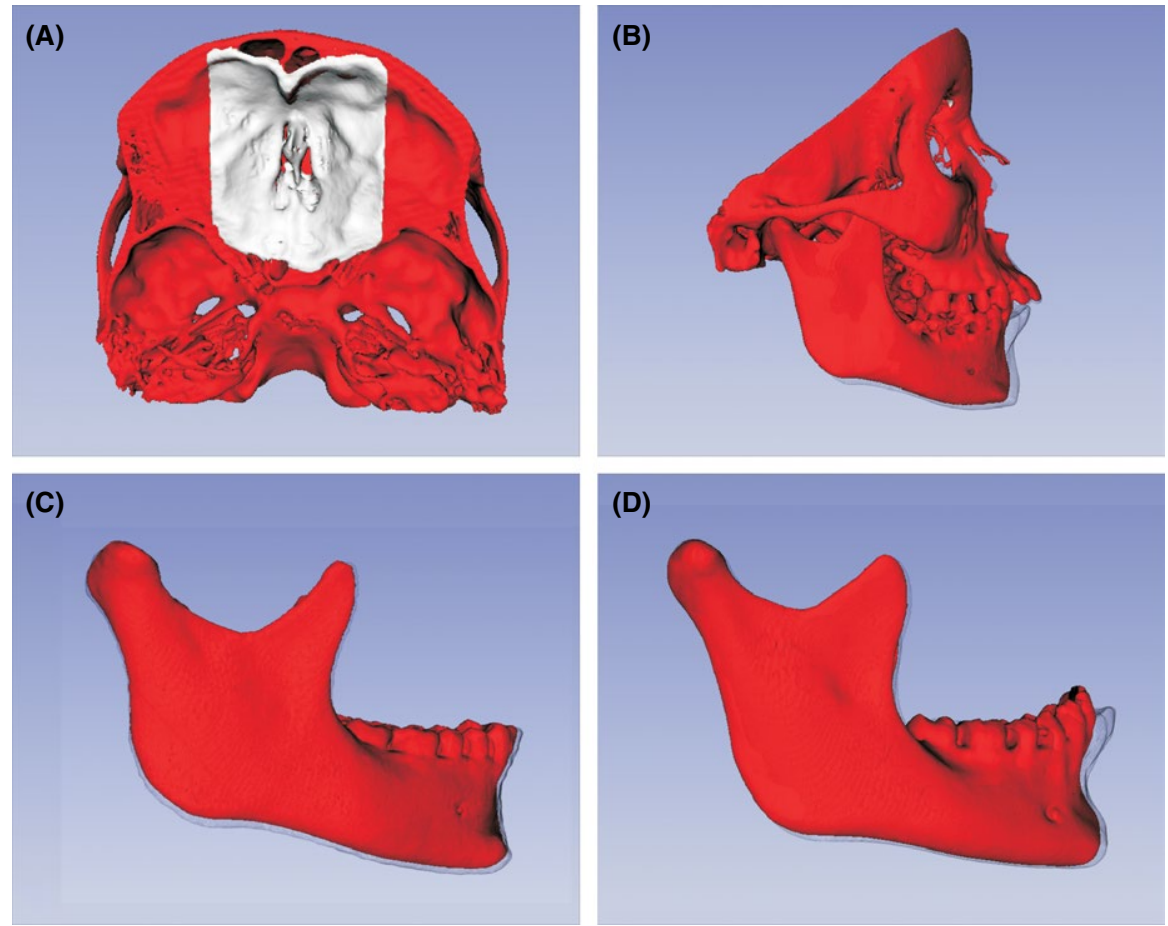

FIGURE 1 Cranial base volumetric superimposition and the 3D models semi-transparent overlays. A, Anterior cranial base superimposition mask. B, Full face displacement after Herbst appliance treatment. C, Mandibular displacement in comparison group individual. D, Mandibular displacement after Herbst appliance treatment. studies using 2D imaging have shown greater skeletal changes with even shorter observational periods ( 6 months). The 3D condylar growth, ranging between 2 and $3 \mathrm{~mm}$, observed in the HAG in this study cannot be considered small. As the CG showed 3D condylar growth ranging between 1 and $2 \mathrm{~mm}$, however, the net differences were not as high as described previously in the literature. The growth of the rami posteriorly was significantly greater in the HAG. Although $0.6 \mathrm{~mm}$ in the inferior region of the rami might be considered small from a clinical point of view, this perspective can change if the short observation period is taken into account. Significant bone deposition along the posterior border of the 
FIGURE 2 Semi-transparent overlays of the 3D models (TO, red; and T1, black mesh), and closest point colour maps in the qualitative assessment of the condylar growth (mandibular regional superimposition). A, Herbst appliance patient. B, Comparison group patient.
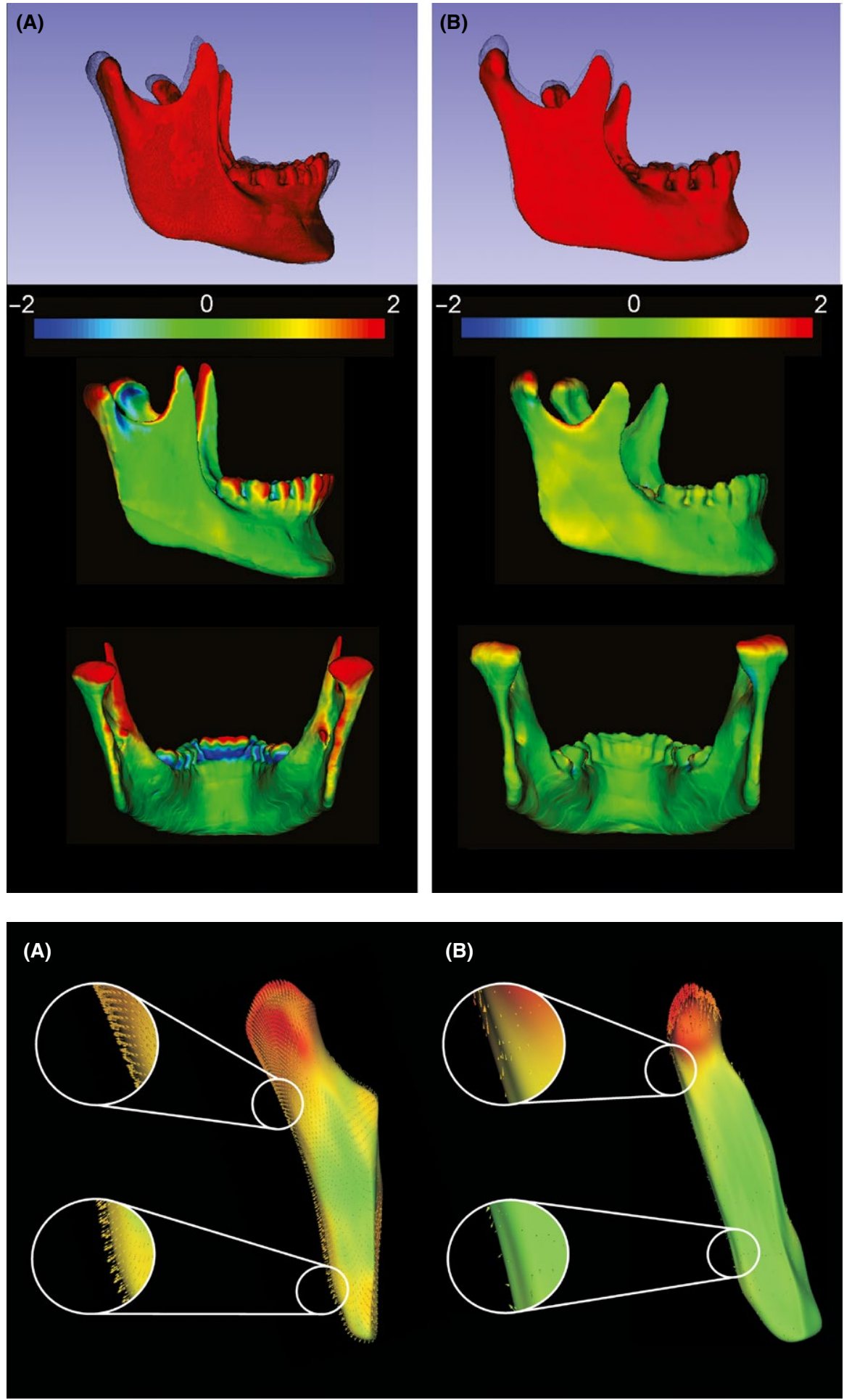

FIGURE 3 Shape correspondence colour mapping with vectors in the qualitative assessment of the condylar and rami growth (mandibular regional superimposition). A, Herbst appliance patient. B, Comparison group subject.

ramus has been reported in experimental studies with juvenile rhesus monkey. ${ }^{11}$

\section{5 | CONCLUSIONS}

Immediately after Herbst therapy, significantly more mandibular forward displacement without pitch was achieved, due to increased bone remodelling of the condyles and rami compared to an untreated sample. Herbst patients presented different magnitude and direction of condylar growth as contrasted to comparison patients.

\section{ACKNOWLEDGEMENTS}

We thank Luana Araujo, Wagner Braga and Luciano Scherrer. Their contribution was crucial for the completion of the current multiinstitutional investigation. This research was partially funded by a grant from the FIP PUC Minas. 


\section{CONFLICT OF INTEREST}

The authors have stated explicitly that there are no conflict of interests in connection with this article.

\section{REFERENCES}

1. Flores-Mir C, Major MP, Major PW. Soft tissue changes with fixed functional appliances in Class II division 1. Angle Orthod. 2006;76:712-720.

2. Baysal A, Uysal T. Soft tissue effects of Twin Block and Herbst appliances in patients with Class II division 1 mandibular retrognathy. Eur J Orthod. 2013;35:71-81.

3. Cozza P, Baccetti T, Franchi L, De Toffol L, McNamara JA Jr. Mandibular changes produced by functional appliances in Class II malocclusion: a systematic review. Am J Orthod Dentofacial Orthop. 2006;129:599. e1-12.

4. Baltromejus S, Ruf S, Pancherz H. Effective temporomandibular joint growth and chin position changes: activator versus Herbst treatment. A cephalometric roentgenographic study. Eur J Orthod. 2002;24:627-637.

5. McGuinness N. Fixed functional appliances show definite skeletal and dental changes in the short term. Eur J Orthod. 2016;38:127-128.

6. Yang X, Zhu Y, Long $\mathrm{H}$, et al. The effectiveness of the Herbst appliance for patients with Class II malocclusion: a meta-analysis. Eur J Orthod. 2016;38:324-333.

7. Deen E, Woods MG. Effects of the Herbst appliance in growing orthodontic patients with different underlying vertical patterns. Aust Orthod J. 2015;31:59-68.

8. Pancherz $\mathrm{H}$. The mechanism of Class II correction in Herbst appliance treatment. A cephalometric investigation. Am J Orthod. 1982;82:104-113.

9. Serbesis-Tsarudis C, Pancherz H. "Effective" TMJ and chin position changes in Class II treatment. Angle Orthod. 2008;78:813-818.

10. Chayanupatkul A, Rabie ABM, Hägg U. Temporomandibular response to early and late removal of bite-jumping devices. Eur $J$ Orthod. 2003;25:465-470

11. Peterson JE, McNamara Jr JA. Temporomandibular joint adaptations associated with Herbst appliance treatment in juvenile rhesus monkeys (Macaca mulatta). Semin Orthod. 2003;9:12-25.

12. Baysal A, Uysal T. Dentoskeletal effects of Twin Block and Herbst ap pliances in patients with Class II division 1 mandibular retrognathy. Eur J Orthod. 2014;36:164-172.

13. Zymperdikas VF, Koretsi V, Papageorgiou SN, Papadopoulos MA Treatment effects of fixed functional appliances in patients with Class II malocclusion: a systematic review and meta-analysis. Eur J Orthod. 2016;38:113-126.

14. Al-Saleh MAQ, Alsufyani N, Flores-Mir C, Nebbe B, Major PW. Changes in temporomandibular joint morphology in class II patients treated with fixed mandibular repositioning and evaluated through 3D imaging: a systematic review. Orthod Craniofac Res. 2015;18:185-201.

15. D'Antò V, Bucci R, Franchi L, Rongo R, Michelotti A, Martina R. Class II functional orthopaedic treatment: a systematic review of systematic reviews. J Oral Rehabil. 2015;42:624-642.

16. Durão AR, Pittayapat P, Rockenbach MIB, et al. Validity of 2D lateral cephalometry in orthodontics: a systematic review. Prog Orthod. 2013;14:31.

17. Pancherz H, Ruf S, Kohlhas P. "Effective condylar growth" and chin position changes in Herbst treatment: a cephalometric roentgenographic long-term study. Am J Orthod Dentofacial Orthop. 1998;114:437-446.

18. Baccetti T, Franchi L, McNamara JA Jr. The Cervical Vertebral Maturation (CVM) method for the assessment of optimal treatment timing in dentofacial orthopedics. Semin Orthod. 2005;11:119-129.

19. Martina R, Cioffi I, Galeotti A, et al. Efficacy of the Sander bitejumping appliance in growing patients with mandibular retrusion: a randomized controlled trial. Orthod Craniofac Res. 2013;16:116-126.

20. Yatabe M, Garib D, Faco R, et al. Mandibular and glenoid fossa changes after bone-anchored maxillary protraction therapy in patients with UCLP: A 3-D preliminary assessment. Angle Orthod 2016. E-pub ahead of print September 26, 2016.

21. Ruellas AC, Tonello C, Gomes LR, et al. Common 3-dimensional coordinate system for assessment of directional changes. Am J Orthod Dentofacial Orthop. 2016;149:645-656.

22. Ruellas AC, Yatabe MS, Souki BQ, et al. 3D Mandibular superimposition: comparison of regions of reference for voxel-based registration. PLoS ONE. 2016;11:e0157625.

23. Solem RC, Ruellas A, Miller A, Kelly K, Ricks-Oddie JL, Cevidanes L. Congenital and acquired mandibular asymmetry: mapping growth and remodeling in 3 dimensions. Am J Orthod Dentofacial Orthop. 2016;150:238-251.

24. Nguyen T, Cevidanes L, Paniagua B, Zhu H, Koerich L, De Clerck H. Use of shape correspondence analysis to quantify skeletal changes associated with bone-anchored Class III correction. Angle Orthod. 2014;84:329-336

25. de Almeida MR, Henriques JFC, de Almeida RR, Ursi W, McNamara Jr JA. Short-term treatment effects produced by the Herbst appliance in the mixed dentition. Angle Orthod. 2005;75:540-547.

How to cite this article: Souki BQ, Vilefort PLC, Oliveira DD, et al. Three-dimensional skeletal mandibular changes associated with Herbst appliance treatment. Orthod Craniofac Res. 2017;20:111-118. https://doi.org/10.1111/ocr.12154 